\title{
Nurses' characteristics and perceptions toward using the electronic health record system as predictors of clinical nursing performance improvement
}

\author{
Ahmad H. Abu Raddaha* \\ Department of Nursing, College of Applied Medical Sciences, Prince Sattam bin Abdulaziz University, Alkharj, Kingdom of \\ Saudi Arabia
}

Received: June 20, 2017

DOI: $10.5430 / \mathrm{cns} . v 5 n 4 \mathrm{p} 32$
Accepted: August 3, 2017

URL: https://doi.org/10.5430/cns.v5n4p32
Online Published: August 8, 2017

\begin{abstract}
Objective: Little and inconclusive knowledge is known about nurses' perceptions toward electronic health record (EHR) systems and how nurses role performance has been affected after using such systems. This study assessed the relationships between nurses' sociodemographic characteristics, history and pattern of computer technology use, and perceptions toward the EHR system with their perceptions regarding improvement of clinical nursing performance after using the system. Predictors of nurses' perception regarding the effect of the EHR system on improving their clinical nursing performance were delineated.

Methods: Descriptive correlational design was used. A standardized self-administered questionnaire was used to collect data from nurses working at a governmental teaching hospital in Muscat, Oman. Nurses were selected randomly from a sampling frame, which consisted of a comprehensive list of employment numbers of nurses at the hospital.

Results: With a response rate of $84.5 \%, 169$ nurses returned completed questionnaires. The majority had highly positive perceptions toward the EHR system. A weakly negative correlation was observed between perceiving that EHR system is improving work performance with increasing level of academic nursing education (rho $=0.17, p=.02$ ). Nurses who reported that it was easy to know how to request a test, record etc. using the EHR system [OR: 3.89 (95\% CI: 1.54, 9.87), $p<.01]$ were more likely perceive the EHR system as an improver to their clinical nursing performance. While, nurses who had completed at least baccalaureate nursing education [OR: 0.41 (95\% CI: 0.19, 0.89), $p=.02$ ] were less likely to perceive the EHR system had improved their performance.

Conclusions: Nurses should be able to demonstrate basic nursing informatics competencies when dealing with computers and software applications used in healthcare settings. Future qualitative studies are encouraged to explore the lived experiences of nurses, in order to develop better understanding to the impact of the EHR system on nursing practice.
\end{abstract}

Key Words: Electronic health record, Nurses, Nursing informatics, Oman, Perceptions, Work performance

\section{INTRODUCTION}

\subsection{Background}

Electronic health record (EHR) systems are becoming integrated into almost every aspect of healthcare. ${ }^{[1,2]}$ The
EHR system is a computerized clinical information system or application that can be used to collect, store, and display patients' information longitudinally throughout their many encounters with a healthcare provider system. ${ }^{[3-7]}$

\footnotetext{
*Correspondence: Ahmad H. Abu Raddaha; Email: a.aburaddaha@psau.edu.sa; Address: Prince Sattam bin Abdulaziz University, College of Applied Medical Sciences, Nursing Department, P.O. Box: 422, Alkharj, 11942, Kingdom of Saudi Arabia.
} 
It is important to understand the impact of these systems on practicing nurses. The perceptions of nurses about the EHR system should be evaluated through assessing the effect on nurses' role performance. EHR systems with a poor fit to workplace needs can lead to more errors related to difficulties in entering or retrieving patients' information or hampered communication and coordination among team members.

There is insufficient and inconclusive knowledge about nurses' perceptions toward EHR systems and how their role performance has been affected after using EHR systems in clinical settings.

\subsection{Research objectives}

The objectives of this research study were to: (1) assess the relationships between nurses' sociodemographic characteristics, history and pattern of computer technology use, and perceptions toward the EHR system with perception regarding improvement of clinical nursing performance while using such system; and (2) estimate predictors of nurses' perception regarding improvement of clinical nursing performance while using the EHR system.

\subsection{Literature review}

Nurses form the largest component of the health workforce, thus implementing a usable EHR by nurses will be a requirement for success. ${ }^{[7]}$ In Lambooij et al.'s study, ${ }^{[8]}$ nurses reported that the quality of patient data was better when the EHR had perceived as easy to use. Evaluation of EHR system use is necessary to ensure that it adequately meets the requirements, expectations and information processing needs of nurses along with other healthcare providers. ${ }^{[9]}$

The advancement of EHR systems related to advancements in information and communication technologies has significant influence on healthcare delivery. ${ }^{[10]}$ Given that nurses play a substantial role in providing and coordinating patient care, the extent to which an EHR system enhances or detracts from nurses' role performance can be expected to affect patient outcomes. ${ }^{[2]}$ That is, understanding nurses' interactions with EHR systems assist in decreasing clinical errors related to disrupted workflow or poor communication, improving nurse job satisfaction, and decreasing turnover rates.

Nursing and healthcare informatics research activities that support EHR system use are urgently needed in order to improve technology-enabled care practices, which is needed and has not yet been widely addressed in most clinical settings. Further, evaluating the use of EHR systems by nurses is critical due to subsequent effect on health care quality. ${ }^{[11]}$ For instance, nurses' use of the EHR system is crucial because it increases the potential to improve patient care through incorporating latest evidence-based practice recommendations by

Published by Sciedu Press such computerized system.

Internationally, inadequate studies have been conducted to assess the use of EHR systems among nurses. ${ }^{[1-3,8,11-25]}$ Nurses acceptance of the EHR is influenced by several factors including the characteristics of EHR, workplace and context of use, characteristics of nurses, usefulness and easiness to use the EHR. ${ }^{[18]}$ In a cross-sectional study among nurses in Taiwan, Lin $^{[24]}$ indicated that perceived ease of use and usefulness of the EHR system on the quality of provided nursing care had positively affected nurses' satisfaction with the system.

Eley et al.'s study ${ }^{[3]}$ evaluated the significant impact of nursing staff perceptions toward the EHR system. They explored barriers to the use of health information and computer technology uptake. They found that EHR use had been influenced by disruptive workflow, insufficient numbers of computer terminals in clinical setting, and nurses motivation to use the EHR system. Hamamura et al.' ${ }^{[26]}$ study showed that the use of EHR system would be facilitated by the presence of IT support, congruence between the functionality of the system with existed workflow, and absence of technological errors/noise in the system. Technical issues such as access speeds and content lag are further challenges with EHR systems. ${ }^{[10]}$ Similarly, studies conducted by Chang et al. ${ }^{[22]}$ and Lee et al. ${ }^{[23]}$ in Taiwan identified presence of slow network speed and user-unfriendly screens as barriers to use the EHR system.

Considering taking nurses' comments and feedbacks regarding the EHR system and involving nurses during EHR system modifications were reported as factors that affect nurses use of the EHR system. ${ }^{[1,27]}$ Besides, Samoutis et al. ${ }^{[13]}$ found that lack of organizational support and inadequate education and training decreased the likelihood of effective use of EHR system by nurses. Training on using the EHR system is necessary and nursing administrators should ensure that such training would be completed by all nurses. ${ }^{[25]}$

In a systematic review, Kruse et al. ${ }^{[28]}$ underscored that efficiency and access-to-data as facilitators to use the EHR system. Whereas, perception of uselessness when using the EHR system was a barrier to use the system. In the same light, responsiveness, ease of learning, sufficient support, and completeness and accurateness of the EHR records were identified as factors that significantly affect nursing performance. ${ }^{[29]}$

Previous research studies showed little evidence on the impact of EHR systems on nurses working in most clinical settings. Recognition of specific facilitators and barriers that may affect a system's use by nurses will address gaps in the 
literature. Furthermore, nursing informatics research that supports improving and reengineering technology-enabled care practices is needed and has not yet been widely realized or addressed. In Sultanate of Oman, a Middle East country in the gulf region, no previous studies have examined the impact of the EHR use on nurses.

Understanding nurses' perceptions toward the EHR system, especially the factors that were likely to affect the likelihood of improving nursing practice while using the system, can enhance nurses' ability to work effectively and efficiently.

\section{Methods}

\subsection{Design}

Descriptive correlational design was used. A self-administered questionnaire was utilized to collect data from March to October 2014.

\subsection{Setting}

Participants were recruited from a governmental teaching hospital located in Muscat, the capital of Sultanate of Oman. The hospital provides a full range of care services, including diagnosis, treatment and rehabilitative services for patients admitted from all socioeconomic levels.

\subsection{Sample and recruitment process}

The study participants were nurses who were employed in the participating hospital. Employment numbers of the nurses at the participating hospital were used as a sample frame. Specifically, nurses were randomly selected from the sample frame if they met the following criteria: (1) been employed in the hospital for a minimum of 3 months. This period allows for enough time for nurses to have valid experience in using the EHR system, (2) used the EHR system to perform some of the job responsibilities, (3) be able to comprehend the English language, and (4) agreed to participate and give informed consent.

At the time of data collection, the total of 200 participants were invited to take part of this study, only 170 agreed to participate, however, one of the participants returned a blank questionnaire. As a result, 169 completed questionnaires used for analyses, with a response rate of $84.5 \%$. Recruitment of nurses was on a voluntary basis, and they were assured anonymity and confidentiality of their responses. The purposes of the study were explained and nurse had been given time to ask questions before making a decision to participate or not. Written informed consents to participate in the study were collected. Along with "a thank you letter", the participants were given a token of appreciation in the form of one 8-GB USB Flash Drive for their time.

\subsection{Measurements}

The self-administered questionnaire consisted of several sections to elicit data about nurses' sociodemographic, clinical, history and pattern of information technology use, perceptions toward the EHR system, along with their perception regarding the improvement of clinical nursing performance by the use of the EHR system.

Nurses' perceptions about the EHR use was assessed using an instrument developed by Oroviogoicoechea et al. ${ }^{[30]}$ The instrument consists of 17 questions, with response options using a five-point Likert rating scale that ranges from "strongly agree" to "strongly disagree". It assesses perceptions, including development of the EHR system and support provided for nurses, characteristics and quality of the EHR system, adaptation of the EHR system to the daily work at the workplace, quality of the documentation associated with the EHR system, and impact of using the EHR system on nurses' work and on the hospital. Cronbach's alpha for all the items included in the different scales was 0.93 .

The perception regarding the improvement of clinical nursing performance while using the EHR system was determined using a single question "Does using the EHR system improve your work performance?", with a Likert scale ranging from " $0=$ Not At All Improving" to " $10=$ Extremely Improving", with a score of $\geq 8$ as a cut-point to indicate high level of clinical improvement.

\subsection{Ethical considerations}

Before commencing the data collection, the study protocol reviewed and approved by the research and ethics committee at a governmental university's college of nursing, as well as at the institutional review board at the participating hospital.

\subsection{Data management and analysis}

The data files were built and statistical analyses were performed using IBM SPSS program for Windows. The entered data were systematically examined for inconsistencies, out-of-range or missing values. Means, standard deviations, minimums and maximums for continuous variables, and frequencies and percentages for categorical variables were calculated. Median score was used to dichotomize continuous variables, when needed. ${ }^{[31-33]}$

Considering the perception of clinical nursing improvement after using the EHR system as a dependent/an outcome variable (i.e., high clinical improvement vs. little and low clinical improvement), Spearman rho correlation coefficient statistics were used to explore the relationships between the study variables with the dichotomized categorical dependent variable. Univariate logistic regression analyses followed by multivariate logistic regression with Wald forward analyses were 
carried-out to identify independent predictors associated with perceived clinical nursing improvement status. Statistical analyses were performed using two-tailed tests with $\alpha=$ 0.05 .

\section{RESUlts}

\subsection{Participants characteristics}

Female constituted $82.2 \%$ of the participants. As shown in Table 1, sixty-eight percent of the participants were between from 30 to 49 years old, and $51.5 \%$ had at least 16 years of nursing experience. The majority $(89.3 \%)$ were staff nurses and expatriate non-Omani citizens $(85.8 \%)$. In relation to the highest educational level completed, almost half of the participants reported completing diploma education. Besides, most of the participants $(82.8 \%)$ were married.

A small proportion (7.7\%) reported that they did not own personal computer or laptop. When asked, "Have you worked with an EHR system elsewhere?", 24.9\%, reported "yes". Almost a third $(34.3 \%$ ) reported that they did not complete formal computer training course, and $65.7 \%$ stated that they usually use computer programs other than the EHR system. Figure 1 shows that almost two third $(67.5 \%)$ of the participants spent at least 1 hour of daily work in using the EHR system.

\subsection{Perceptions about using the EHR system}

In general, the participants had highly positive perceptions toward the EHR system. Figure 2 illustrates the magnitude of reported perceptions. They agreed mostly that data collected and registered into the EHR system are important for caring their patients, the EHR is conforming and imitating their work routine, easy-to-use and easy-to-learn EHR, and cooperative attitude of the personnel who are responsible on EHR system. On the other side, the lowest agreements linked to the response-time needed to make improvements in the EHR system, understandability of people who are responsible on EHR system to their clinical problems and the degree to which their suggestions were taken into account about the EHR. Figure 3 shows that $77.5 \%$ of the participants perceived that the EHR improves their daily nursing performance.

\subsection{Correlations with the perception that the EHR sys- tem improves clinical nursing performance}

The relationships between the participants' sociodemographic characteristics, history and pattern of information technology experiences, and their perceptions concerning the effect of EHR system on improving their daily nursing performance were explored using Spearman's rho correlation coefficients. The correlation matrix in Table 2 shows that perceiving that EHR system is improving work performance Published by Sciedu Press was weakly correlated with increasing years of nursing experience (rho $=0.16, p=.04)$. On the other hand, a weakly negative correlation was observed between perceiving that EHR system is improving work performance with increasing level of academic nursing education ( $r h o=0.17, p=.02$ ).

Table 1. Descriptions of participants characteristics

\begin{tabular}{|c|c|c|}
\hline Variable & Frequency & $\%$ \\
\hline \multicolumn{3}{|l|}{ Gender } \\
\hline - Female & 139 & 82.2 \\
\hline \multicolumn{3}{|l|}{ Age (in years) } \\
\hline - $\quad<29$ & 29 & 17.2 \\
\hline - $\quad 30-39$ & 70 & 41.4 \\
\hline - $40-49$ & 45 & 26.6 \\
\hline - $\quad 50-59$ & 20 & 11.8 \\
\hline - $\quad>60$ & 5 & 3.0 \\
\hline \multicolumn{3}{|l|}{ Job Title } \\
\hline - $\quad$ Staff Nurse & 151 & 89.3 \\
\hline - $\quad$ Charge/Administrator Nurse & 18 & 10.7 \\
\hline \multicolumn{3}{|l|}{ Years of Nursing Experience } \\
\hline$\bullet \quad<5$ & 22 & 13.0 \\
\hline - $6-10$ & 28 & 16.6 \\
\hline - $\quad 11-15$ & 32 & 18.9 \\
\hline - $16-20$ & 45 & 26.6 \\
\hline - $\quad 21-25$ & 24 & 14.2 \\
\hline - $\quad>26$ & 18 & 10.7 \\
\hline \multicolumn{3}{|l|}{ Nationality } \\
\hline - Omani & 24 & 14.2 \\
\hline - Expats & 145 & 85.8 \\
\hline \multicolumn{3}{|l|}{ Highest Educational Level } \\
\hline - College (Diploma/Associated) & 85 & 50.3 \\
\hline - Baccalaureate and Above & 84 & 49.7 \\
\hline \multicolumn{3}{|l|}{ Marital Status } \\
\hline - $\quad$ Married & 140 & 82.8 \\
\hline - Unmarried & 29 & 17.2 \\
\hline \multicolumn{3}{|c|}{ Do you own a personal computer or laptop? } \\
\hline - Yes & 156 & 92.3 \\
\hline \multicolumn{3}{|l|}{$\begin{array}{l}\text { Have you worked with an EHR system } \\
\text { elsewhere? }\end{array}$} \\
\hline - Yes & 42 & 24.9 \\
\hline \multicolumn{3}{|c|}{$\begin{array}{l}\text { Have you completed formal computer training } \\
\text { courses? }\end{array}$} \\
\hline - Yes & 58 & 34.3 \\
\hline \multicolumn{3}{|l|}{$\begin{array}{l}\text { Do you usually use a computer software } \\
\text { program other than the EHR System? }\end{array}$} \\
\hline - Yes & 111 & 65.7 \\
\hline
\end{tabular}

\subsection{Predictors of perceiving EHR System as an im- prover to clinical nursing performance}

Univariate logistic regression performed to assess impact of participants' sociodemographic characteristics, history and pattern of information technology experiences, with their perceptions toward the use of EHR system on the likelihood of perceiving the EHR system as an improver to clinical nursing performance as a dependent variable. 


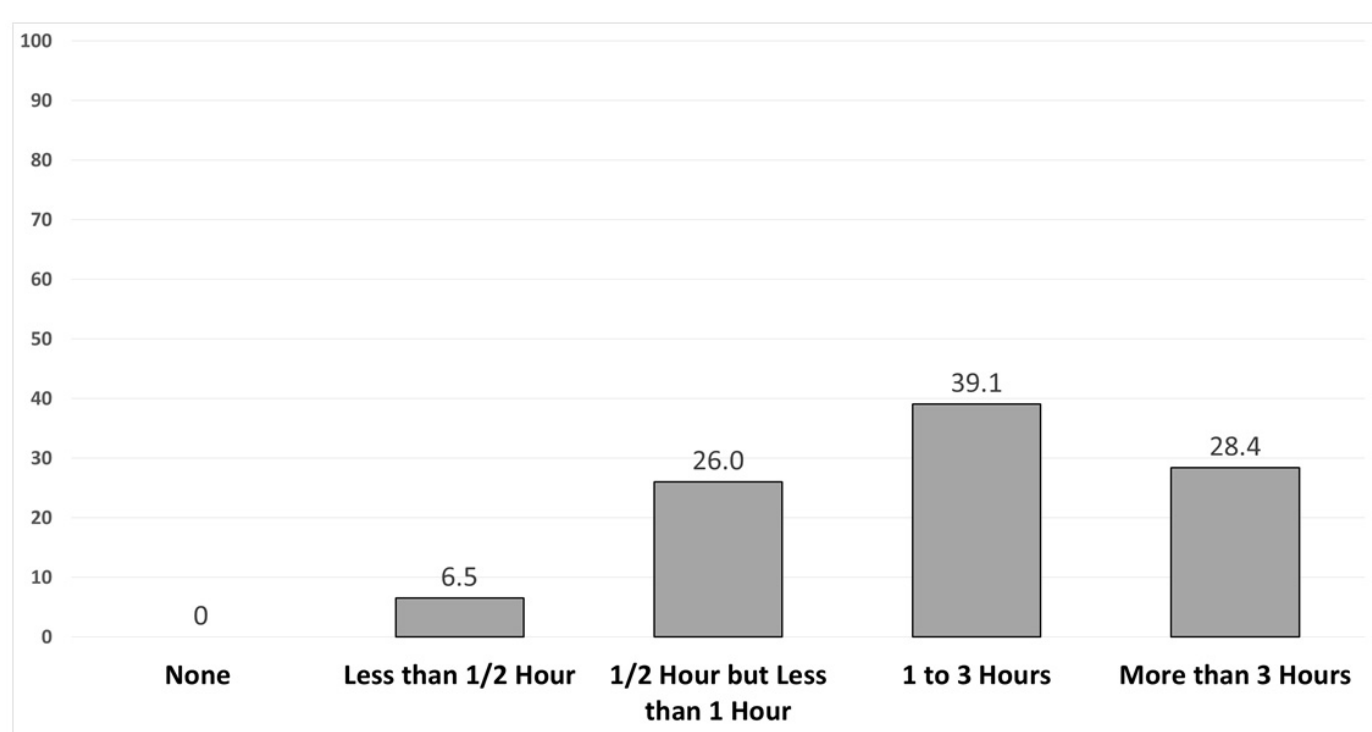

Figure 1. Participants' time spent using the EHR system during daily clinical nursing duties

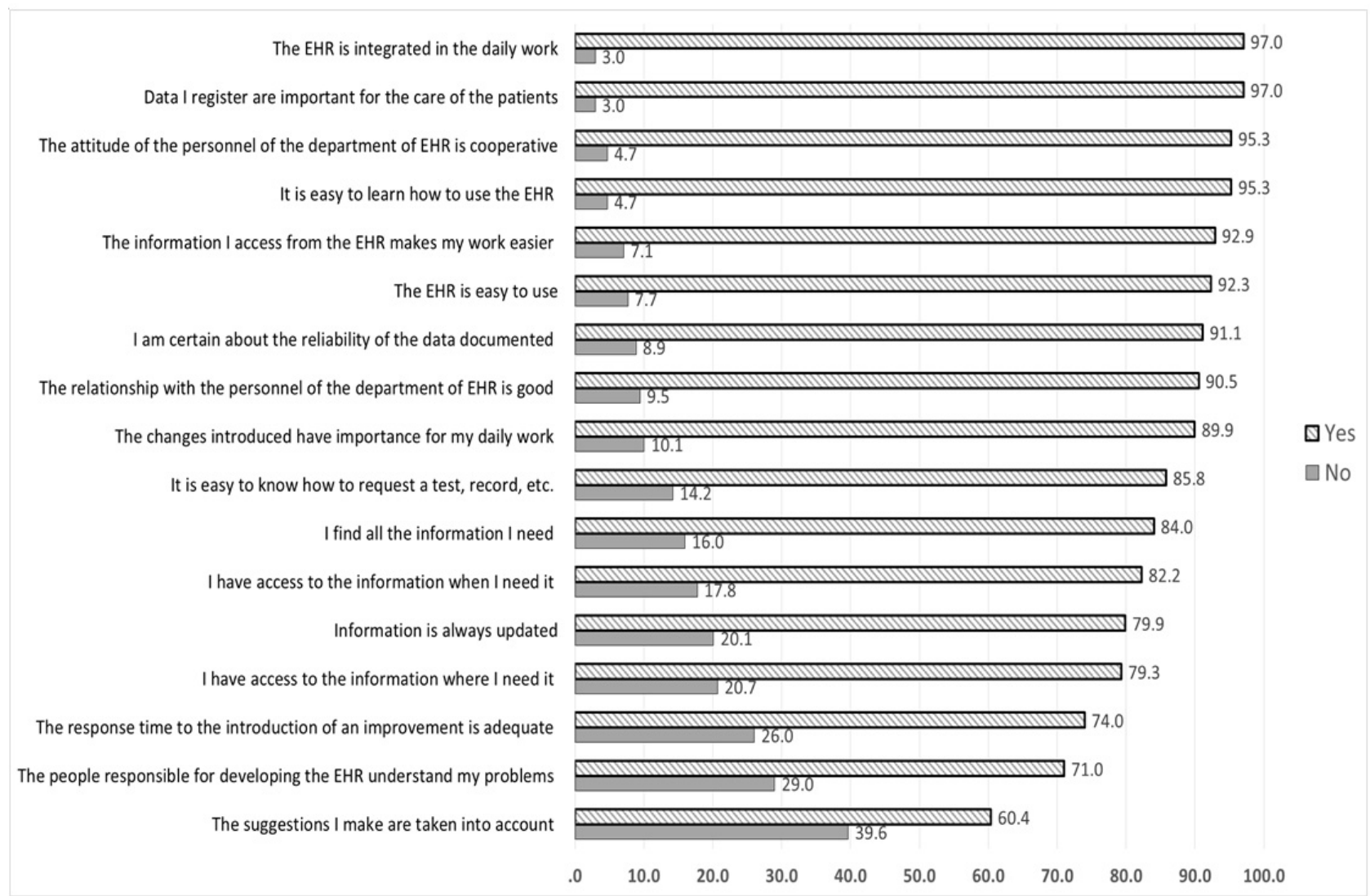

Figure 2. Nature of participants' perceptions toward the use of EHR system

Table 3 shows the univariate logistic regression analysis re- request a test, record, etc. [OR: 3.70 (95\% CI: 1.50, 9.14), sults. It shows that nurses who had at least 16 years nursing $p<.01]$, and had reported that the EHR information is upexperience [OR: 2.16 (95\% CI: 1.03, 4.54), $p=.04$ ], had dated [OR: 2.16 (95\% CI: 1.03, 4.54), $p=.04$ ] were statistireported that it easy to know how to use the EHR system cally significantly more likely to perceive the EHR system 
as an improver to clinical nursing performance. On the other hand, nurses who had completed at least baccalaureate in nursing [OR: 0.43 (95\% CI: 0.20, 0.91), $p=.03$ ] were statistically significantly less likely perceiving the EHR system improving to their clinical performance.

Independent variables with univariate logistic regression scores with $p<.10$ were candidate in the multivariate analysis. Two variables retained after performing the multivariate logistic regression analysis with Wald forward selection at a $p<.05$. The final multivariate logistic regression model shown in Table 4 was statistically significant, $\chi^{2}(2, \mathrm{~N}=169)=13.044, p=.001$. As shown in the final model, nurses were more likely perceive the EHR system as an improver to their clinical nursing performance if they thought that it was easy to know how to request a test, record etc. using the EHR system [OR: 3.89 (95\% CI: 1.54, 9.87), $p<.01]$, while controlling for all other variables in the model. Whereas, nurses who had completed at least baccalaureate nursing education [OR: 0.41 (95\% CI: 0.19, 0.89), $p=.02$ ] were less likely perceived the EHR system improving their performance, while controlling for all other variables in the model.

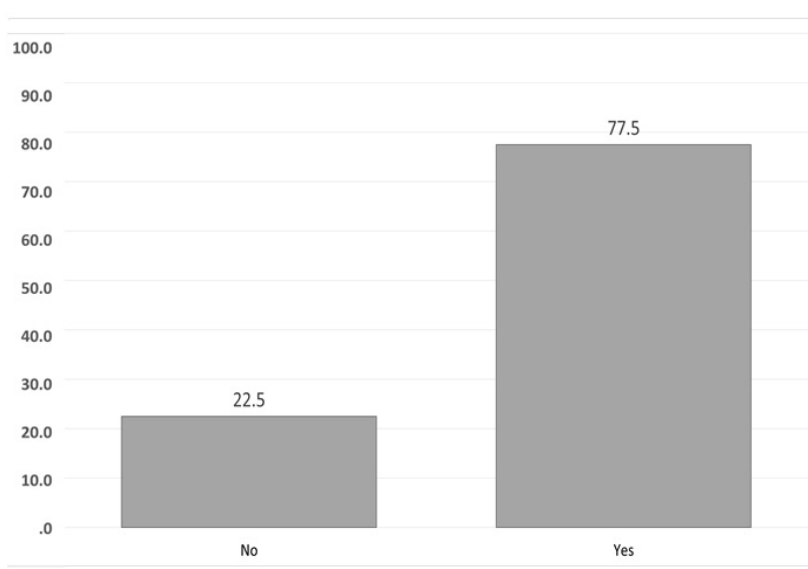

Figure 3. Perceptions that EHR system improves daily clinical nursing performance

Table 2. Spearman's rho correlation coefficients between participants' characteristics with high improvement of clinical nursing performance

\begin{tabular}{|c|c|c|}
\hline Variable & Spearman's rho & $p$ \\
\hline Gender $^{\S}$ & -0.01 & .90 \\
\hline $\operatorname{Age}^{€}$ & -0.10 & .19 \\
\hline Job Title ${ }^{z}$ & 0.00 & .98 \\
\hline Years of Nursing Experience $\xi$ & 0.16 & .04 \\
\hline Nationality ${ }^{\varphi}$ & -0.11 & .17 \\
\hline Educational Level ${ }^{£}$ & -0.17 & .02 \\
\hline Marital Status $\zeta$ & 0.09 & .23 \\
\hline Do you own a personal computer or laptop? ${ }^{\eta}$ & 0.06 & .46 \\
\hline Have you worked with an EHR system elsewhere? ${ }^{\eta}$ & 0.11 & .14 \\
\hline Have you completed formal computer training courses? ${ }^{\eta}$ & 0.09 & .24 \\
\hline Do you usually use a computer software program other than the EHR System ${ }^{\eta}$ & -0.06 & .43 \\
\hline
\end{tabular}

Note. Improvement of clinical nursing performance while using EHR system was coded as $0=$ "No or Little", $1=$ "High". Abbreviations:

${ }^{\S}$ Coded: $0=$ "Female", 1 = "Male"; ${ }^{€}$ Coded: $0=$ "38 Years and Above", 1 = "Less than 38 Years"; " Coded: $0=$ "Staff Nurse", $1=$ "Charge/Administrator Nurse"; ${ }^{\xi}$ Coded: $0=$ "Less than 16 Years", 1 = "16 Years and Above"; ${ }^{\varphi}$ Coded: 0 = "Non Omani", 1 = "Omani"; ${ }^{£}$ Coded: $0=$ "College (Diploma/Associated", 1 = "Baccalaureate and Above"; ${ }^{\zeta}$ Coded: $0=$ "Unmarried", $1=$ "Married"; " Coded: $0=$ "No", $1=$ "Yes"

\section{Discussion}

This study showed findings that are worth to discuss. In this study, age was explored if it could be a possible barrier or facilitator to the EHR system use. In line with Eley et al.' ${ }^{[3]}$ study in Australia, age was neither a barrier nor a facilitator to the use of EHR system among nurses. This finding is significant given the homogenous large number of study participants, who were assigned randomly.

Nurses with increasing number of years of experience perceived the EHR system as an improver to their clinical nurs- ing performance. This is contrary to the findings reported Saarinen and $\mathrm{Aho}^{[12]}$ who examined the effect of years of nursing experience on time that nurses spent to document their activities. They found that nurses with 10 to 20 years of nursing experience had spent significantly more time to document their nursing activities. As only about quarter of participants had worked with an EHR system elsewhere, training sessions on using the EHR system that target nursing staff regardless to their years of experience in nursing would expand and more support safe, effective, and efficient nursing practice. 
Table 3. Univariate logistic regression analysis of independent variables and improvement of clinical nursing performance while using EHR as a dependent variable

\begin{tabular}{|c|c|c|c|c|c|c|}
\hline \multirow{2}{*}{ Variable } & \multirow{2}{*}{ B } & \multirow{2}{*}{ S.E. } & \multirow{2}{*}{ Sig. } & \multirow{2}{*}{$\begin{array}{l}\text { Odds } \\
\text { Ratio }\end{array}$} & \multicolumn{2}{|c|}{ 95\% C.I. for Odds Ratio } \\
\hline & & & & & Lower & Upper \\
\hline Gender $[$ Male $]$ & -.06 & .48 & .90 & .94 & .37 & 2.40 \\
\hline Age $[$ Less than 38 Years $]$ & -.49 & .37 & .19 & .61 & .30 & 1.28 \\
\hline Job Title [Charge/Administrator Nurse] & .02 & .60 & .98 & 1.02 & .31 & 3.29 \\
\hline Years of Nursing Experience [At least 16 Years] & .77 & .38 & .04 & 2.16 & 1.03 & 4.54 \\
\hline Nationality [Omani] & -.65 & .48 & .17 & .52 & .20 & 1.33 \\
\hline Highest Educational Level [At least Baccalaureate] & -.85 & .38 & .03 & .43 & .20 & .91 \\
\hline Marital Status [Married] & .54 & .45 & .23 & 1.72 & .71 & 4.18 \\
\hline Owning a Personal Computer or Laptop [Yes] & .47 & .63 & .46 & 1.59 & .46 & 5.50 \\
\hline Previous Working with an EHR System Elsewhere $[Y e s]$ & .70 & .49 & .15 & 2.02 & .78 & 5.24 \\
\hline Completion of Formal Computer Training Courses [Yes] & .48 & .41 & .24 & 1.62 & .72 & 3.62 \\
\hline Usual Use a Computer Software Program other than the EHR System [Yes] & -.32 & .40 & .43 & .73 & .33 & 1.60 \\
\hline It is easy to learn how to use the EHR [Yes] & 1.32 & .73 & .07 & 3.74 & .89 & 15.71 \\
\hline The EHR is easy to use [Yes] & .85 & .60 & .16 & 2.33 & .71 & 7.59 \\
\hline Data I register are important for the care of the patients [Yes] & .86 & .93 & .35 & 2.37 & .38 & 14.73 \\
\hline The EHR is integrated in the daily work [Yes] & -.15 & 1.13 & .89 & .86 & .09 & 7.91 \\
\hline It is easy to know how to request a test, record, etc. [Yes] & 1.31 & .46 & .00 & 3.70 & 1.50 & 9.14 \\
\hline The information I access from the EHR makes my work easier [Yes] & .99 & .62 & .11 & 2.68 & .80 & 9.00 \\
\hline The relationship with the personnel of the department of EHR is good [Yes] & .82 & .55 & .14 & 2.27 & .77 & 6.71 \\
\hline The suggestions I make are taken into account [Yes] & .69 & .37 & .07 & 1.99 & .96 & 4.12 \\
\hline The attitude of the personnel of the department of EHR is cooperative [Yes] & -.74 & 1.09 & .50 & .48 & .06 & 4.02 \\
\hline The response time to the introduction of an improvement is adequate [Yes] & .67 & .40 & .09 & 1.96 & .90 & 4.26 \\
\hline The people responsible for developing the EHR understand my problems [Yes] & .62 & .39 & .11 & 1.86 & .87 & 3.97 \\
\hline The changes introduced have importance for my daily work [Yes] & .72 & .55 & .19 & 2.05 & .70 & 5.95 \\
\hline I have access to the information where I need it $[Y e s]$ & .03 & .45 & .95 & 1.03 & .42 & 2.49 \\
\hline I have access to the information when I need it $[Y e s]$ & -.06 & .48 & .90 & .94 & .37 & 2.40 \\
\hline I am certain about the reliability of the data documented [Yes] & -.49 & .37 & .19 & .61 & .30 & 1.28 \\
\hline I find all the information I need [Yes] & .02 & .60 & .98 & 1.02 & .31 & 3.29 \\
\hline Information is always updated [Yes] & .77 & .38 & .04 & 2.16 & 1.03 & 4.54 \\
\hline
\end{tabular}

Note. Improvement of clinical nursing performance while using EHR system was coded as $0=$ "No or Little", $1=$ "High"

Table 4. Multivariate logistic regression of variables and improvement of clinical nursing performance while using EHR as a dependent variable

\begin{tabular}{lllllll}
\hline Variable & \multirow{2}{*}{ B } & \multirow{2}{*}{ S.E. } & \multirow{2}{*}{ Sig. } & \multicolumn{2}{l}{ Odds } & \multicolumn{2}{l}{ 95\% C.I. for Odds Ratio } \\
\cline { 5 - 7 } & & & & Ratio & Lower & Upper \\
\hline Highest Educational Level [At least Baccalaureate] & -.90 & .40 & .02 & .41 & .19 & .89 \\
It is easy to know how to request a test, record, etc. [Yes] & 1.36 & .47 & .00 & 3.89 & 1.54 & 9.87 \\
Constant & .63 & .47 & .18 & 1.87 & & \\
\hline
\end{tabular}

Note. Improvement of clinical nursing performance while using EHR system was coded as $0=$ "No or Little", $1=$ "High"

Only about a third of the participants reported completing a computer-training course. Nursing curricula should include nursing informatics competencies courses to prepare future nurses on using the technology, especially in this era of technology-oriented healthcare settings. Furthermore, nurses should be able to demonstrate basic competencies when dealing with information systems such as basic familiarity with the use of computers, computer software applications for creating and sharing professional documents, and electronic communication tools. ${ }^{[10,34-37]}$

The findings showed that nurses highly perceived that data entered into the EHR system were important for caring their patients. They perceived the EHR system as congruent with 
their work routine, easy-to-use and easy-to-learn. EHR systems should support workflow processes. A highly usable EHR system must be efficient. Selecting an EHR system that improves time efficiency could improve nurses' role performance. ${ }^{[6]}$ It should allow increased access to patient information without interruption to workflow and inter-professional communication.

A large proportion of nurses reported that long response-time would be needed to make improvements in the EHR, the people responsible on EHR system often did not recognize their clinical problems pertinent to the EHR system, and yet they did not take their suggestions about the EHR into account. Difficulty of getting technological support was also found to be the principal barrier faced by nurses while using the EHR system in Samoutis et al.'s study in Cyprus ${ }^{[13]}$ and Chang et al.'s study in Taiwan. ${ }^{[22]}$ Likewise, the support of information technology team along with offering education/training on the EHR system were reported as facilitators of the EHR system use. ${ }^{[26]}$ The presence of a responsive help system that effectively supports end users is very important to be addressed. ${ }^{[29,38]}$

Nurses showed high positive perception toward the availability of updated data through the EHR. This finding is congruent with the findings of Kruse et al. ${ }^{[28]}$ They showed that transition of data and efficiency were significant facilitators to use the EHR system. Especially with nursing shortages, updated documentation is necessary during clinical nursing practice. Nurses use large volumes of data during their clinical practice such as order lists, problem lists, vital signs graphs, and medication lists. EHR should allow access to updated data for all of these functions with little switching between multiple windows.

The findings showed that only $60 \%$ of nurses reported that their suggestions for improving the EHR system were taken into account. Nurses should be involved in designing, modifying/reengineering the healthcare technology they use to meet their professional performance needs. ${ }^{[39]}$ Additionally, creating different-specialty collaborative task force would expedite resolution of different users' concerns regarding the EHR system. ${ }^{[27]}$

Compared with nurses who completed their diploma nursing education, nurses who completed baccalaureate degrees or higher were less likely to perceive the EHR system as helpful in improving their clinical nursing performance. One possible explanation for this unique finding is that they had higher level of expectations from the EHR system. Future qualitative studies should be conducted to explore the lived experiences of nurses who earned at least baccalaureate degrees in order to develop netter understanding to their reported

\section{perceptions.}

The ability of nurses to know how to request a test, record, etc. was a determinant for perceiving the EHR system as helpful in improving the performance of their clinical duties. Poor EHR system interface is a barrier to use the system. ${ }^{[26]}$ EHR system should be easy to navigate, learn and understand. ${ }^{[7,40]}$ Too many clicks and screen flips, and information design required horizontal as well as vertical scrolling, liberal use of color, and low contrast with data objects were found as barriers for system usability. ${ }^{[11]}$

\section{Conclusions}

This study assessed the relationships between nurses' perceptions regarding improvement of clinical nursing performance while using the EHR system with their sociodemographic characteristics, history and pattern of computer technology use, and perceptions toward the EHR system. The findings are noteworthy given the homogenous large number of study participants who were assigned randomly.

Participating nurses reported their perceptions toward the EHR system using during clinical nursing performance, with the majority agreeing that the system allowed for collecting data necessary and relevant for caring their patients, and that the system is conforming and imitating their work routine, easy-to-use and easy-to-learn.

Among nurses, age was not found to be as a barrier or a facilitator to the use of EHR system. Moreover, nurses with greater experience had perceived the EHR system as an improver to their clinical nursing performance. As only a small proportion of participants reported working with an EHR system elsewhere or completing a computer-training course, training sessions on using the EHR system would support providing safe, effective, and efficient nursing care.

Response-time by the people responsible on EHR system was perceived as too long. Further, nurses reported that some of their clinical problems were not understood. Increasing the level of support for nurses, who are the end-users, of the system, is highly recommended.

Nurses who reported that it is easy to know how to use the EHR system to request a test, record, etc., were more likely perceive the EHR system as improving to their clinical nursing performance. On the other hand, nurses who completed at least baccalaureate in nursing education were less likely perceive the EHR system as an improver to their clinical nursing performance. EHR system should be easy to use, navigate, learn and understand, without having to press many clicks to achieve the required nursing daily clinical duties. 


\subsection{Limitations and strengths}

Although relying on self-reporting decreases reliability, one can assume that the responses of the participants had adequate level of reliability as anonymity and voluntary recruitment of participants were assured. Given that it was a cross-sectional study, making definitive statements regarding causality is not possible. The large sample size and using random sampling technique, increase secondary validity possibility for the study findings. Due to the dearth of evidence about nurses perceptions toward the EHR system in Sultanate of Oman and worldwide, this study added distinct and unique clinical nursing evidence concerning the use EHR systems by nurses.

\subsection{Implications and recommendations}

This study provided findings about the perceptions of nurses toward the use of EHR system; however, exploring the perceptions of other healthcare providers toward the system is warranted.

Given that study participants with at least baccalaureate educations and who do not have long years of experience showed low scores in perceptions toward the impact of using the EHR system on their clinical performance, future qualitative re- search work is necessary to explore their lived experiences in order to improve nursing role performance.

Policy makers are encouraged to expand nurses' contributions regarding the EHR system modifications and customizations. Allowing nurses' voice to be more heard would improve and streamline the EHR support for nurses while they provided care for different recipients.

Nurse educators are encouraged to revise nursing curricula as to ensure that nursing students are prepared to demonstrate basic informatics competencies during their education. More dedicated training specifically geared toward using the EHR system is also needed during clinical nursing education. Contemporary nursing curricula address the need to prepare future nurses with basics of information technologies. ${ }^{[10,34-37]}$

\section{ACKNOWLEDGements}

College of Nursing's Dean Fund at Sultan Qaboos University has financially supported this research study.

\section{CONFlicts OF InTEREST Disclosure}

There are no conflicts of interest to declare.

\section{REFERENCES}

[1] Donati A, Gabbanelli V, Pantanetti S, et al. The impact of a clinical information system in an intensive care unit. J Clin Monit Comput. 2008; 22(1): 31-6. https://doi.org/10.1007/s10877-007-9 104-x

[2] Kossman SP, Scheidenhelm SL. Nurses' perceptions of the impact of electronic health records on work and patient outcomes. Comput Inform Nurs. 2008; 26(2): 69-77. https ://doi.org/10.1097/01 . NCN . 0000304775.40531 .67

[3] Eley R, Fallon T, Soar J, et al. Barriers to use of information and computer technology by Australia's nurses: a national survey. J Clin Nurs. 2009; 18(8): 1151-8. https ://doi.org/10.1111/j.1365 $-2702.2008 .02336 . \mathrm{x}$

[4] McLane S. Designing an EMR planning process based on staff attitudes toward and opinions about computers in healthcare. Comput Inform Nurs. 2005; 23(2): 85-92. PMid: 15772509. https: //doi .org/10.1097/00024665-200503000-00008

[5] Hebda T, Czar P. Handbook of informatics for nurses \& healthcare professionals. 5th ed. Boston: Pearson; 2013.

[6] Saba VK, McCormick KA. Essentials of nursing informatics. $6^{\text {th }}$ ed. New York, NY: McGraw-Hill Publications; 2015.

[7] Sewell JP. Informatics and nursing: opportunities and challenges. $5^{\text {th }}$ ed. Philadelphia, PA: Lippincott Williams and Wilkins; 2015.

[8] Lambooij MS, Drewes HW, Koster F. Use of electronic medical records and quality of patient data: different reaction patterns of doctors and nurses to the hospital organization. BMC Med Inform Decis Mak. 2017; 17(1): 17. https://doi.org/10.1186/s129 11-017-0412-x
[9] Kushniruk AW, Patel VL. Cognitive and usability engineering methods for the evaluation of clinical information systems. J Biomed Inform. 2004; 37(1): 56-76. https ://doi .org/10.1016/j.jbi. 2004.01 .003

[10] Risling T. Educating the nurses of 2025: Technology trends of the next decade. Nurse Educ Pract. 2017; 22: 89-92. https ://doi.or g/10.1016/j.nepr.2016.12.007

[11] Rose AF, Schnipper JL, Park ER, et al. Using qualitative studies to improve the usability of an EMR. J Biomed Inform. 2005; 38(1): 51-60. https://doi.org/10.1016/j.jbi.2004.11.006

[12] Saarinen K, Aho M. Does the implementation of a clinical information system decrease the time intensive care nurses spend on documentation of care? Acta Anaesthesiol Scand. 2005; 49(1): 62-5 https://doi.org/10.1111/j.1399-6576.2005.00546.x

[13] Samoutis G, Soteriades ES, Kounalakis DK, et al. Implementation of an electronic medical record system in previously computer-naive primary care centres: a pilot study from Cyprus. Inform Prim Care. 2007; 15(4): 207-16. PMid: 18237477.

[14] Wong DH, Gallegos Y, Weinger MB, et al. Changes in intensive care unit nurse task activity after installation of a third-generation intensive care unit information system. Crit Care Med. 2003; 31(10): 2488-94. https://doi.org/10.1097/01.CCM.0000089637.53301.EF

[15] Dowding DW, Turley M, Garrido T. Nurses' use of an integrated electronic health record: results of a case site analysis. Informatics for Health \& Social Care. 2014: 1-17. https : //doi .org/10.310 9/17538157.2014.948169

[16] Habibi-Koolaee M, Safdari R, Bouraghi H. Nurses readiness and electronic health records. Acta Informatica Medica. 2015; 23(2): 105-7. https://doi.org/10.5455/aim.2015.23.105-107 
[17] Juliet BV, Sudha M. Perception and Attitude of Staff Nurses towards Electronic Health Records. Asian J Nurs Educ Res. 2013; 3(2): 6.

[18] Strudwick G, Hall LM. Nurse acceptance of electronic health record technology: a literature review. J Res Nurs. 2015; 20(7): 596-607. https://doi.org/10.1177/1744987115615658

[19] Marasovic C, Kenney C, Elliott D, et al. A comparison of nursing activities associated with manual and automated documentation in an Australian intensive care unit. Comput Nurs. 1997; 15(4): 205-11. PMid: 9260381

[20] Minda S, Brundage DJ. Time differences in handwritten and computer documentation of nursing assessment. Comput Nurs. 1994; 12(6): 277-9. PMid: 7812894

[21] Pierpont GL, Thilgen D. Effect of computerized charting on nursing activity in intensive care. Crit Care Med. 1995; 23(6): 1067-73. https://doi.org/10.1097/00003246-199506000-00012

[22] Chang CP, Lee TT, Liu CH, et al. Nurses' Experiences of an Initial and Reimplemented Electronic Health Record Use. Comput Inform Nurs. 2016; 34(4): 183-90. https://doi.org/10.1097/CIN.00 00000000000222

[23] Lee TT, Chang CP. Nurses' Experiences of an Initial and ReImplemented Electronic Health Record Use. Stud Health Technol Inform. 2016; 225: 802-3. PMid: 27332349.

[24] Lin HC. Nurses' Satisfaction With Using Nursing Information Systems From Technology Acceptance Model and Information Systems Success Model Perspectives: A Reductionist Approach. Comput Inform Nurs. 2017; 35(2): 91-9. https://doi .org/10.1097/CIN . 0000000000000293

[25] Verma M, Gupta S. Problems Faced by Nurses in Use of Electronic Health Records During Clinical Practice. Stud Health Technol Inform. 2016; 225: 985-6. PMid: 27332444.

[26] Hamamura FD, Withy K, Hughes K. Identifying Barriers in the Use of Electronic Health Records in Hawai'i. Hawaii J Med Public Health. 2017; 76(3 Suppl 1): 28-35. PMid: 28435756.

[27] Romero MR, Staub A. Specialty Task Force: A Strategic Component to Electronic Health Record (EHR) Optimization. Stud Health Technol Inform. 2016; 225: 1051-2. PMid: 27332478.

[28] Kruse CS, Kothman K, Anerobi K, et al. Adoption Factors of the Electronic Health Record: A Systematic Review. JMIR Medical Informatics. 2016; 4(2): e19. https ://doi .org/10.2196/medinf orm. 5525
[29] Cohen JF, Coleman E, Kangethe MJ. An importance-performance analysis of hospital information system attributes: A nurses' perspective. Int J Med Inform. 2016; 86: 82-90. https://doi .org/10.1 016/j.ijmedinf . 2015.10.010

[30] Oroviogoicoechea C, Watson R, Beortegui E, et al. Nurses' perception of the use of computerised information systems in practice: questionnaire development. J Clin Nurs. 2010; 19(1-2): 240-8. https://doi.org/10.1111/j.1365-2702.2009.03003.x

[31] Nunnally JC, Bernstein IH. Psychometric theory. 3rd ed. New York: McGraw-Hill; 1994.

[32] Plichta Kellar S, Kelvin EA. Munro's statistical methods for health care research. $6^{\text {th }}$ ed. Philadelphia, PA: Wolters Kluwer Health/Lippincott Williams \& Wilkins; 2012.

[33] Pallant J. SPSS Survival Manual: A Step by Step Guide to Data Analysis Using IBM Spss. $2^{\text {nd }}$ ed. Maidenhead, Berkshire. U.K.; New York, NY: Open University Press; 2013.

[34] Nagle LM, Crosby K, Frisch N, et al. Developing entry-to-practice nursing informatics competencies for registered nurses. Stud Health Technol Inform. 2014; 201: 356-63. PMid: 24943567.

[35] Sensmeier J, Anderson C, Shaw T. International Evolution of TIGER Informatics Competencies. Stud Health Technol Inform. 2017; 232: 69-76. PMid: 28106584.

[36] Shaw T, Sensmeier J, Anderson C. The Evolution of the TIGER Initiative. Comput Inform Nurs. 2017; 35(6): 278-80. https: //doi.org/10.1097/CIN.0000000000000369

[37] van Houwelingen CT, Moerman AH, Ettema RG, et al. Competencies required for nursing telehealth activities: A Delphi-study. Nurse Educ Today. 2016; 39: 50-62. https ://doi.org/10.1016/j.nedt.2 015.12 .025

[38] Patterson ES, Nguyen AD, Halloran JP, et al. Human factors barriers to the effective use of ten HIV clinical reminders. J Am Med Inform Assoc. 2004; 11(1): 50-9. https://doi.org/10.1197/ja mia.M1364

[39] Kahouei M, Zadeh JM, Roghani PS. The evaluation of the compatibility of electronic patient record (EPR) system with nurses' management needs in a developing country. Int J Med Inform. 2015; 84(4): 263-70. https://doi.org/10.1016/j.ijmedinf . 2014. 12.006

[40] Ash JS, Berg M, Coiera E. Some unintended consequences of information technology in health care: the nature of patient care information system-related errors. J Am Med Inform Assoc. 2004; 11(2): 104-12. https://doi.org/10.1197/jamia.M1471 